\title{
Mutation in the mitochondrial 12S rRNA gene in two families from Mongolia with matrilineal aminoglycoside ototoxicity
}

Department of Human Genetics, P O Box 980033, Medical College of Virginia, Richmond, VA 23298, USA

A Pandya

$\mathrm{X}$ Xia

W E Nance

\section{Department of} Maternal and Child Health, Ulaanbaatar, Mongolia

J Radnaabazar

J Batsuuri

B Dangaansuren

Department of Pediatrics, Cedars-Sinai Medical Center, Los Angeles, CA 90048, USA N Fischel-Ghodsian

Correspondence to: Dr Pandya.

Received 9 May 1996 Revised version accepted for publication

3 September 1996

\begin{abstract}
A Pandya, X Xia, J Radnaabazar, J Batsuuri, B Dangaansuren, N Fischel-Ghodsian,
\end{abstract} W E Nance

\begin{abstract}
Irreversible hearing loss is a catastrophic complication of treatment with aminoglycoside antibiotics such as streptomycin, gentamycin, and kanamycin. Many kindreds showing a matrilineal pattern of inheritance of this trait have been described in China where the widespread use of aminoglycoside antibiotics accounts for approximately $25 \%$ of profound deafness in some districts. Because of the characteristic inheritance pattern, mitochondrial DNA (mtDNA) mutations were postulated to be the cause of the deafness in these pedigrees. In 1993 it was shown that an $A$ to $G$ substitution at base pair 1555 of the mitochondrial $12 \mathrm{~S}$ ribosomal RNA gene was the only mutation common to all the families with aminoglycoside ototoxicity.
\end{abstract}

We ascertained three Mongolian pedigrees from the School for the Deaf and Blind in Ulaanbaatar, all of which contained multiple affected subjects with streptomycin induced deafness in a pattern consistent with matrilineal transmission. Amplified mtDNA, obtained from transformed lymphoblastoid cell lines using previously described primers, showed the $A$ to $G$ point mutation in the $12 \mathrm{~S}$ rRNA gene in two of the three families by restriction analysis as well as direct sequencing. No other example of this substitution was found among 400 control samples from Mongolians with normal hearing.

We have thus confirmed the clinical relevance of the $1555 \mathrm{~A}$ to $\mathrm{G}$ mitochondrial mutation in the 12S rRNA gene by identifying it in affected subjects with familial aminoglycoside ototoxicity in another ethnic group. In countries where aminoglycosides are widely used, genetic counselling and screening of high risk families before the use of these drugs could have a dramatic effect on the incidence of deafness.

(F Med Genet 1997;34:169-172)

Keywords: mitochondrial $12 \mathrm{~S}$ rRNA gene; Mongolia; matrilineal aminoglycoside ototoxicity.

Hereditary deafness is a heterogeneous group of genetic entities which can be distinguished by their clinical manifestations, mode of inher- itance, and map location. In $10-20 \%$ of cases, deafness is associated with clinical features which permit the diagnosis of a specific syndrome while the remaining cases are considered non-syndromic. Most nonsyndromic deafness (60-70\%) shows a recessive pattern of inheritance, $20-30 \%$ of cases show dominant transmission, and $2-3 \%$ are $\mathrm{X}$ linked.

Matrilineal or mitochondrial transmission of aminoglycoside induced deafness was first suggested by Higashi ${ }^{1}$ after studying two Japanese families and a review of several Chinese pedigrees reported earlier. Jaber et al ${ }^{2}$ studied a large Israeli-Arab kindred with hereditary nonsyndromic deafness where the deafness could be traced back five generations to one common female ancestor. Interestingly, based on segregation analysis, they proposed a digenic model with one locus being mitochondrial, and the other autosomal recessive. A similar pattern of matrilinear transmission has been seen in several smaller Chinese pedigrees of aminoglycoside induced deafness. ${ }^{3}$ In both the digenic non-syndromic deafness pedigree and the families with aminoglycoside induced deafness, a homoplasmic mitochondrial ribosomal RNA (rRNA) A to G substitution at nucleotide position 1555 was identified. ${ }^{4}$ This mutation occurs at a highly conserved region of the $12 \mathrm{~S}$ rRNA gene, where aminoglycosides are known to bind and where mutations conferring aminoglycoside resistance have been described in other species. ${ }^{4} \mathrm{~A}$ small proportion of people with aminoglycoside ototoxicity but no family history of the disease also harbour the same rRNA mutation. ${ }^{5}$ Of the various other sequence changes reported by Prezant et al, ${ }^{4}$ the 663 A to $G$ substitution in the $12 S$ rRNA gene and the $1736 \mathrm{~A}$ to $\mathrm{G}$ substitution in the $16 \mathrm{~S}$ rRNA gene were also present in the subjects they studied with the aminoglycoside induced toxicity. These variants were found in about $11 \%$ and $10 \%$ of the normal Asian population, respectively. Since four of their controls with both of these mutations received streptomycin with no ill effects, these changes are unlikely to cause deafness by themselves.

In the present study, five subjects from three Mongolian families (fig 1) were screened for the $663 \mathrm{~A}$ to $\mathrm{G}$ and $1555 \mathrm{~A}$ to $\mathrm{G}$ changes in the $12 S$ rRNA gene, and for the $1736 \mathrm{~A}$ to $\mathrm{G}$ change in the $16 \mathrm{~S}$ rRNA gene. The families were ascertained through probands at the School for Deaf and Blind in Ulaanbaatar, 
Family 1

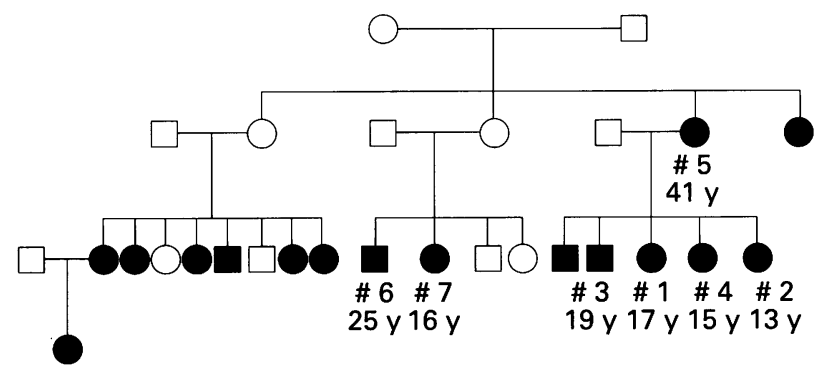

Family 2

Family 3
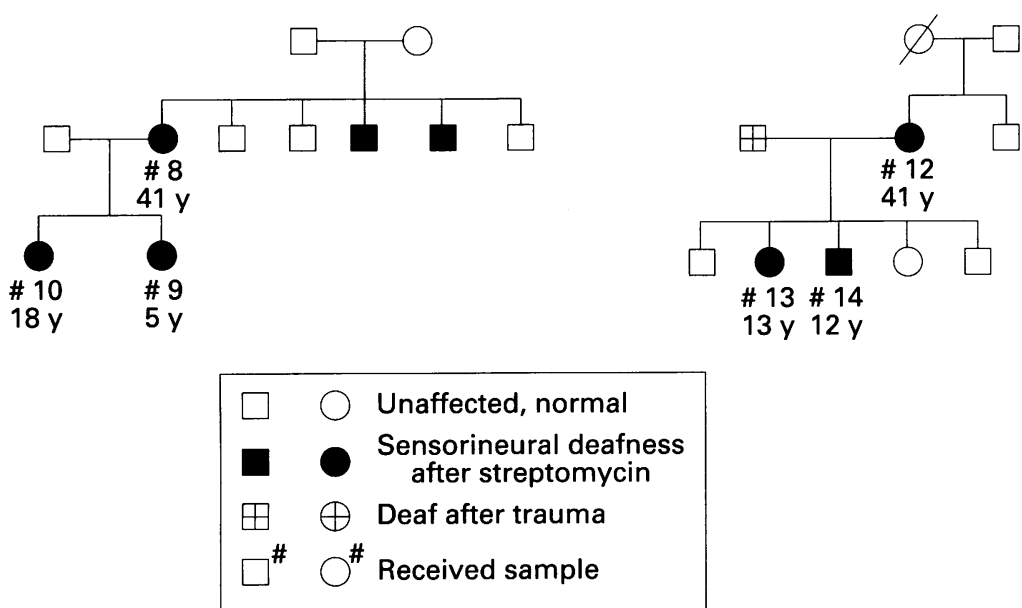

Figure 1 Pedigrees of the three families.

Mongolia. Blood samples from 14 subjects from three independent families were received, and immortalised lymphoblastoid cell lines were successfully established on five of them DNA was isolated from cells using the Puregene DNA isolation kit marketed by Gentra Systems Inc. Additional samples from 400

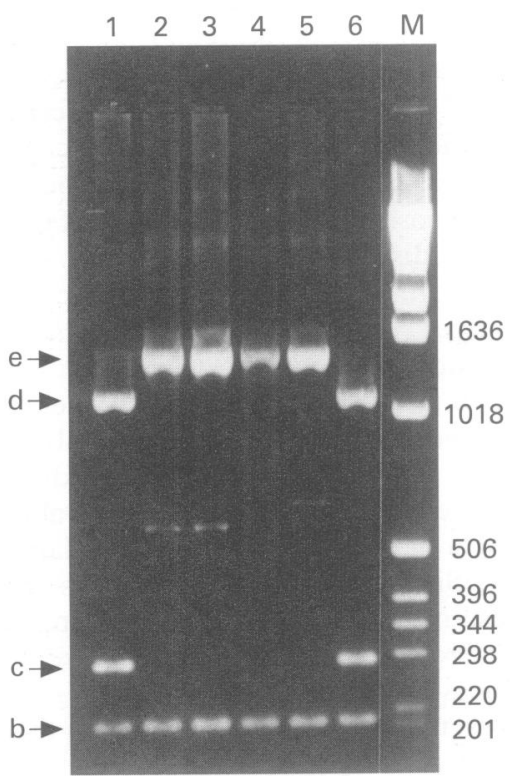

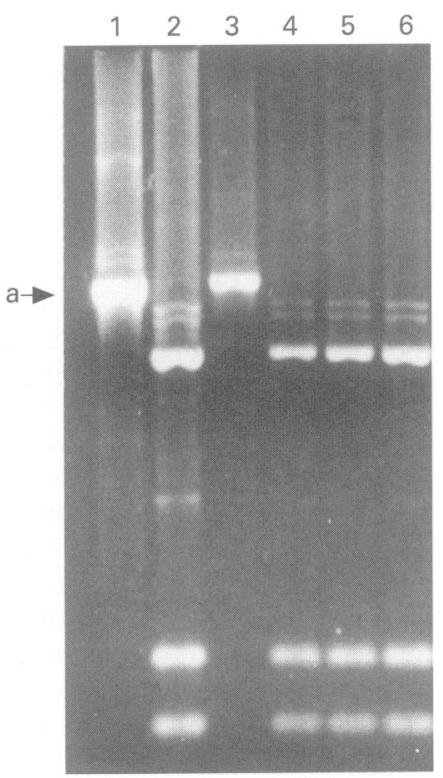

Figure 2 Restriction endonuclease digestion of DNA from $(A)$ affected probands and $(B)$ normal subjects. $(A)$ shows subjects $3,6,7,10$, and 12 under lanes 2 to 6 , a normal control in lane 1 , and a $1 \mathrm{~kb}$ ladder as a molecular marker in lane $M$. All except subject 12 harbour the $1555 A$ to $G$ mutation. (B) shows DNA from blood spots of normal unaffected people from Mongolia, undigested in lane 1 and 3 and digested in lanes 2 and 4 to 10 . None of the samples studied shows this mutation.
Mongolian subjects with normal hearing were sent as $5 \mathrm{~mm}$ blood spots on a filter paper. For isolation of DNA from blood spots we used the organic extraction method described by Desalle et al with slight modification. Our yield from the latter was in the range of 7 to 15 $\mu \mathrm{g} / \mathrm{ml}$. The mutation at $1555 \mathrm{~A}$ to $\mathrm{G}$ has been described as the most invariant in people with streptomycin induced deafness. To study this change in our samples, DNA was amplified in a Perkin Elmer 9600 thermal cycler with primers described by Prezant et al. ${ }^{4}$ The reaction mixture included $500 \mathrm{ng}$ DNA, $10 \mathrm{pmol}$ of each primer, $200 \mu \mathrm{mol} / 1 \mathrm{dNTP} \mathrm{mix}, 1.5 \mathrm{mmol} / 1$ $\mathrm{MgCl}_{2}$, and $2.5 \mathrm{U} \mathrm{Taq}$ polymerase in a final volume of $25 \mu \mathrm{l}$. PCR conditions for amplification were as follows: initial denaturation at $95^{\circ} \mathrm{C}$ for five minutes, followed by 35 cycles of denaturation $\left(95^{\circ} \mathrm{C}\right.$, one minute), annealing $\left(60^{\circ} \mathrm{C}\right.$, one minute), and extension $\left(72^{\circ} \mathrm{C}\right.$, one minute 30 seconds). Ten micrograms of the amplified product were subjected to restriction enzyme digestion with Alw26I, since the 1555 A to $\mathrm{G}$ mutation abolishes the restriction site for this enzyme. Undigested samples show a $1605 \mathrm{bp}$ product (labelled $\mathrm{a}$ in fig 2B). In digested samples normal controls show three bands, b, c, d, which are approximately 206, 293 , and 1106 bp in length while affected subjects exhibit only two bands, 206 and $1399 \mathrm{bp}$ in size (bands b and e, respectively). Products were analysed by electrophoresis in $1.5 \%$ Seakem LE agarose (FMC bioproduct). As seen in fig 2A, four of the five affected subjects have only two bands approximately 206 and $1399 \mathrm{bp}$ in size compared to the three bands observed in digested samples from normal controls. The nature of the substitution at the Alw26I site was subsequently identified by direct sequencing of the PCR product using the Sequenase PCR product sequencing kit marketed by USB (fig 3A). The substitutions at nt663 and nt 1736 were also tested for by direct sequencing of PCR amplified products (fig 3B, C). Interestingly, all three subjects from the first family and subject 12 from the third pedigree had both of these mutations, while subject 10 from the second pedigree had neither. Thus, although subject 12 in family 3 did not carry the 1555 A to $G$ mutation, she had both the variant changes. To date, all those with aminoglycoside ototoxicity studied for molecular changes have shown the 1555 A to $G$ muta- N tion. Thus, the absence of this well defined N mutation in subject 12 with matrilineal transmission of the aminoglycoside ototoxicity is 0 unique and highly suggestive that other mitochondrial mutations or nuclear genes could be ? involved in this disorder. In keeping with this possibility Prezant et al recently reported the isolation of a novel yeast gene that confers neomycin resistance to yeast transformants. The $\stackrel{\mathbb{Q}}{\varrho}$ father in this pedigree has deafness secondary to trauma; however, the mother and the two 8 children all have a history of aminoglycoside induced deafness.

In order to evaluate the apparent association between these mutations and the aminoglycoside induced hearing loss and to determine if they are polymorphic in the Mongolian popu- 


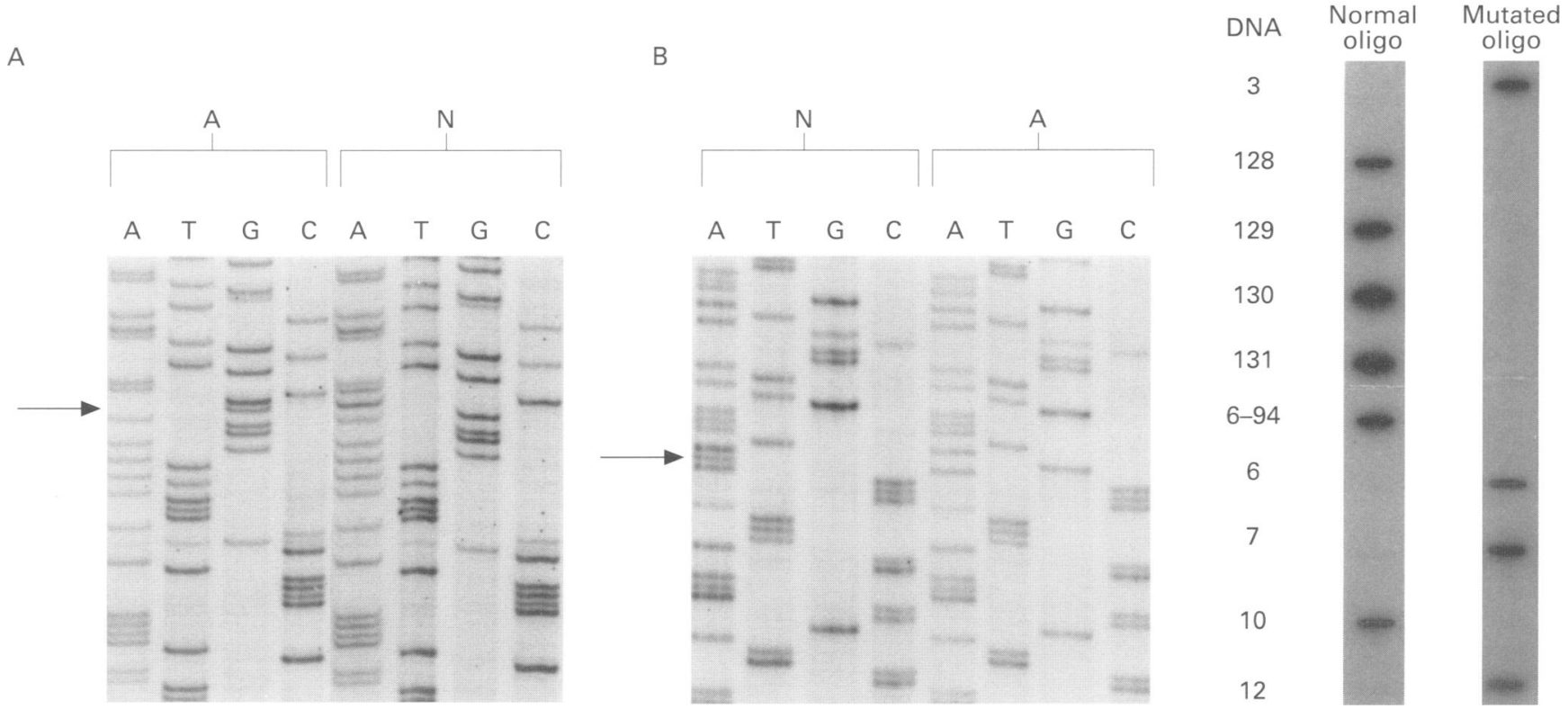

Figure 3 Detection of mutations. (A) Identification of the $1555 \mathrm{~A}$ to $\mathrm{G}$ change in subject 6 , affected with sensorineural deafness from family 1 and a normal control by direct sequencing between nucleotides 1262 and 1625 of the amplified product. The $A$ to $G$ substitution is denoted by the arrow. (B) Identification of the $1736 \mathrm{~A}$ to $\mathrm{G}$ change in the $16 \mathrm{~S} r R N A$ gene by direct sequencing. Results on subject 3 , affected with sensorineural deafness, from family 1 and a normal control by direct sequencing between nucleotides 1262 and 1900 of the amplified product. The $A$ to $G$ substitution is denoted by the arrow. Results were confirmed on the reverse strand and in two different experiments. (C) Identification of the $663 \mathrm{~A}$ to $G$ substitution by allele specific oligonucleotide hybridisation. DNA from affected subjects (Nos 3, 6, 7, 10, and 12) and normal controls hybridised to the normal and mutated oligonucleotides. All subjects except No 10 hybridised with the mutated oligonucleotide indicating that they harbour the mutation.

Table 1 Summary of mutations in the three pedigrees and normal controls

\begin{tabular}{llll}
\hline & 1555 A to G & 663 A to G & 1736 A to $G$ \\
\hline Family 1 & + & + & + \\
Family 2 & + & - & - \\
Family 3 & - & + & + \\
Controls & $0 / 400$ & $17 / 400$ & $18 / 400$ \\
\hline
\end{tabular}

lation we analysed samples from 400 control subjects from Mongolia who had normal hearing by anamnestic history. DNA isolated from 400 blood spots on filter paper was amplified and subjected to restriction endonuclease digestion for the $1555 \mathrm{~A}$ to $\mathrm{G}$ change. The 663 $A$ to $G$ and 1736 A to $G$ substitutions were detected by the hybridisation of amplified mitochondrial DNA with normal and mutant oligomers using a modification of the method for allele specific oligonucleotides described by Thein et $a l^{8}$ The oligonucleotides used to detect the 663 change were 20 base pairs from nucleotide 654 to 673 ; for the 1736 substitution it was 19 base pairs from 1727 to 1745 . $^{\circ}$ The $1555 \mathrm{~A}$ to $\mathrm{G}$ change was absent in all these samples (fig 2B), while the 663 and 1736nt substitutions were detected in $17 / 400$ and $18 / 400$ of the samples respectively (table 1 ). Fourteen subjects with the 663 change also carried the 1736 change.

We concluded that the $1555 \mathrm{~A}$ to $\mathrm{G}$ substitution, which is located in the highly conserved region of the $12 \mathrm{~S}$ rRNA mitochondrial gene, is responsible for aminoglycoside sensitivity in two of the three families. Within the limits of our testing the mutations were homoplasmic in both families. This mutation was absent in the 400 controls from Mongolia. The two other mutations, $663 \mathrm{~A}$ to $\mathrm{G}$ and 1736 A to $G$, which are found with a frequency of
$10-11 \%$ in the Chinese population, were detected in four of the five affected subjects we studied, but only $4-5 \%$ of the Mongolian sample with normal hearing. The mutations were detected together in two of the three affected families, but only $3.5 \%$ of the control subjects who had normal hearing by history $\left(\chi^{2}=16.8,1\right.$ $\mathrm{df}, \mathrm{p} \leq 0.001)$. The population of Mongolia numbers about 2 million, of whom a quarter live in Ullanbatar and another $15 \%$ in much smaller urban areas. At least $40 \%$ of the rural population still lead nomadic lives as they have for centuries. The population is divided into at least 15 ethnic subgroups, the largest of which (the Hoth) accounts for about $70 \%$ of the total population. Although the distribution and frequency of the $1555 \mathrm{~A}$ to $\mathrm{G}$ change within these subgroups remains to be determined, the avoidance of the use of aminoglycosides by the matrilineal relatives of subjects with drug induced ototoxicity would provide at least one effective strategy for reducing the incidence of deafness in the Mongolian population.

1 Higashi $\mathrm{K}$. Unique inheritance of streptomycin-induced deafness. Clin Genet 1989;35:433-6.

2 Jaber L, Shohat M, Bu X, et al. Sensorineural deafness inherited as a tissue specific mitochondrial disorder. $\mathcal{f} \mathrm{Med}$ Genet 1992;29:86-90.

$3 \mathrm{Hu}$ DN, Qiu WQ, Wu BT, et al. Genetic aspects of antibiotic induced deafness: mitochondrial inheritance. $7 \mathrm{Med}$ Genet 1991;28:79-83.

4 Prezant TR, Agapian JV, Bohlman MC, et al. Mitochondria ribosomal RNA mutation associated with both antibioticinduced and nonsyndromic deafness. Nat Genet 1993;4: 289-94.

5 Fischel-Ghodsian N, Prezant TR, Bu X, Oztas S. Mitochondrial ribosomal RNA gene mutation in a patient with sporadic aminoglycoside ototoxicity. Am $f$ Otolaryngol 1993; 14:399-403.

6 Desalle $\mathrm{R}$, Williams $\mathrm{AK}$, George $M$. Isolation and characterization of animal mitochondrial DNA. Methods Enzymol 1993;224:176-204. 
7 Prezant TR, Chaltraw WE Jr, Fischel-Ghodsian N. Aminoglycoside toxicity: the isolation of a yeast gene
involved in aminoglycoside resistance. Am $\mathscr{f}$ Hum Genet 1995;57:A182.

8 Thein SL. The use of synthetic oligonucleotides as specific hybridization probes in the diagnosis of genetic disorders.
.
In: Davies KE, ed. Human genetic disease analysis: a practical approach. Oxford: IRL, 1993:21-33.

Anderson S, Bankier AT, Barrell BG, et al. Sequence and organization of the human mitochondrial genome. Nature 1981;290:457-65. 